\title{
Helicobacter Pylori-Beyond the Gut
}

\author{
Dr Anubhav Chauhan ${ }^{1, *}$, Dr Rajan Sood ${ }^{2}$ \\ ${ }^{I}$ M.S Ophthalmology, Senior Resident, Deptt. of Ophthalmology, Dr Yashwant Singh Parmar Govt. Medical \\ College, Nahan, District Sirmour, Himachal Pradesh, India \\ ${ }^{2}$ M.S Surgery, Assistant Professor, Deptt. of Surgery, Dr Yashwant Singh Parmar Govt. Medical College, \\ Nahan, District Sirmour, Himachal Pradesh, India
}

${ }^{*}$ Corresponding Author: Dr Anubhav Chauhan, M.S Ophthalmology, Senior Resident, Deptt. of Ophthalmology, Dr Yashwant Singh Parmar Govt. Medical College, Nahan, District Sirmour, Himachal Pradesh, India. Email: Chauhan.anubhav2@gmail.com

\section{ARTICLE}

A number of articles involving Helicobacter Pylori can be seen in various worldwide journals but majority of the time, only the gastrointestinal tract is talked about. The role of Helicobacter pylori in causing gastritis and gastrointestinal malignancy is well known. But, besides the gastrointestinal tract, it can also cause diseases of the eye, brain, heart, blood, lungs and the reproductive system. An adequate knowledge/information needs to be shared among the medical professionals of various specialities regarding the organism.

This bacterium can be associated with various conditions like glaucoma, central serous chorioretinopathy, ocular adnexal mucosa associated lymphoid tissue lymphoma, anterior uveitis, blepharitis, ${ }^{[1]}$ Sjogren syndrome, anterior ischemic optic neuropathy, cerebrovascular diseases, migraine, Alzheimer's disease, epilepsy, Parkinson's disease, multiple sclerosis, peripheral neuropathies ${ }^{[2]}$ and dry eye ${ }^{[3]}$ along with serious oral cavity diseases like periodontal disease, recurrent aphthous stomatitis, squamous cell carcinoma, burning, halitosis, ${ }^{[4]}$ leukoplakia and lichen planus. ${ }^{[5]}$ Idiopathic thrombocytopenic purpura, iron deficiency anemia, vitamin B12 deficiency, diabetes mellitus, stroke, lung cancer, preeclampsia, metabolic syndrome, raised triglyceride and blood pressure levels are also noteworthy associations with this bacterium. ${ }^{[6]}$

Hence, a complete systemic examination is recommended in any case having tests positive for Helicobacter Pylori.

\section{REFERENCES}

[1] Saccà SC, Vagge A, Pulliero A, Izzotti A.Helicobacter pylori Infection and Eye Diseases: A Systematic Review. Medicine 2014 ; 93(28).

[2] Yaghoobi G, Rezvani MR, Heidari E. Helicobacter pylori and eye diseases in an Iranian hospital. African Journal of Microbiology Research 2013; 7(38): 4677 4679.

[3] Blomberg L, Hauschild S, Gockeln R, Brewitt $\mathrm{H}$. The dry eye syndrome and the gastral helicobacter pylori infection: Pilot study about a possible existing epidemiological relationship. Investigative Ophthalmology \& Visual Science 2004; 45(13):3903.

[4] Adler I, Muiño A, Aguas S, Harada L, Diaz M, Lence A, et al.Helicobacter pylori and oral pathology: Relationship with the gastric infection.World J Gastroenterol 2014 ; 20(29): 9922-9935.

[5] Kazanowska-Dygdala M,Dus I,Radwan-Oczko M. The presence of Helicobacter pylori in oral cavities of patients with leukoplakia and oral lichen planus.J Appl Oral Sci 2016; 24(1):18-23. 
[6] Diaconu S, Predescu A, Moldoveanu A, Pop C, Fierbințeanu-Braticevici C. Helicobacter pylori infection: old and new. Journal of Medicine and Life 2017; 10(2):112-117.

Citation: Dr Anubhav Chauhan, Dr Rajan Sood, Helicobacter Pylori-Beyond the Gut. ARC Journal of Cancer Science 2018; 4(2):12-13. DOI: http://dx.doi.org/10.20431/2455-6009.0402003

Copyright: (C) 2018 Authors. This is an open-access article distributed under the terms of the Creative Commons Attribution License, which permits unrestricted use, distribution, and reproduction in any medium, provided the original author and source are credited. 